\title{
UN Office for Disaster Risk Reduction (2018)
}

\author{
Marie Aronsson-Storrier*
}

The UN Office for Disaster Risk Reduction (UNDRR) ${ }^{1}$ undertook a lot of significant activities and initiatives in 2018 to further the DRR agenda and promote and support the implementation of the Sendai Framework for DRR around the globe. Upon the request of the Open-ended Intergovernmental Expert Working Group on indicators and terminology relating to DRR (OEIWG), ${ }^{2}$ the UNDRR has taken the lead on the development of 'minimum standards and metadata for disaster-related data, statistics and analysis,' ${ }^{3}$ as well as of 'methodologies for the measurement of indicators and the processing of statistical data with relevant technical partners.' ${ }^{4}$ In 2018, highlights included the launching of the Sendai Framework Monitor, the publication of the Technical guidance for monitoring and reporting on progress in achieving the global targets of the Sendai Framework for Disaster Risk Reduction, and the initiation of the Global Risk Assessment Framework.

\section{Sendai Framework Monitor and Recording of Voluntary Commitments}

The Sendai Framework Monitor went live on 1 March 2018, providing states with the opportunity to record their progress against the identified targets and indicators. ${ }^{5}$ In addition to reporting against the targets and indicators developed by the OEIWG, starting in July 2018, states can also opt to set up their own customised targets and indicators to which they are to report. As of 31 October

* Lecturer, University of Reading.

1 Previously UNISDR; acronym changed in May 2019.

2 Established through UNGA, 'Establishment of an open- ended intergovernmental expert working group on indicators and terminology relating to disaster risk reduction' (25 June 2015) UN Doc A/RES/ 69/ 284.

3 UNGA, 'Report of the open-ended intergovernmental expert working group on indicators and terminology relating to disaster risk reduction' (1 December 2016) UN Doc A/ 71/ 644, para. $20(\mathrm{a})$.

4 Ibid., para. $20(\mathrm{~b})$.

5 The Monitor is available at <https://sendaimonitor.unisdr.org/> last accessed (as any subsequent URL) on 26 June 2016. 
2018, 96 states had started to use the Sendai Framework Monitoring system, although reporting against actual targets was still limited. ${ }^{6}$

In addition to the Sendai Framework Monitoring tool(s) for states, in December 2018, the UNDRR also launched the Sendai Framework Voluntary Commitments system, where stakeholders ${ }^{7}$ working on the Sendai Framework can log their voluntary commitments online. ${ }^{8}$ The Voluntary Commitments stems from the mandate provided to the UNDRR by the UNGA at the adoption of the Sendai Framework, ${ }^{9}$ and is a significant step forward in the UNDRR's work in supporting its implementation.

The Voluntary Commitments online platform is open access and supports the work of stakeholders as well as of the UNDRR. In relation to the former, the platform presents an opportunity for stakeholders to increase the visibility of themselves and their initiatives on a global level, while learning from and finding potential areas for collaboration with, other stakeholders. At the same time, the UNDRR can monitor the progress made by stakeholders with reference to the targets and indicators, while also working together with stakeholders to reduce disaster risk.

It should be noted that the Voluntary Commitments online platform is not designed as a place to share aspirational aims; rather it is a space where stakeholders record actual commitments and progress. In order further to enhance accountability, the Platform has an embedded notifications system which reminds stakeholders to provide details of the progress made in reaction to each of their commitments, either as a fulfilment or as periodic progress. Missing set deadlines will alter the status of the relevant commitment and thus make the failure to report progress visible to other stakeholders, as well as to international governmental organisations and governments.

6 See UNDRR, 'Global Assessment Report on Disaster Risk Reduction 2019' (UN 2019) 220. Out of the 79 States which reported against the indicators (as opposed to providing background information) 63 supplied data for at least 12 months on Target A (mortality), with 53 reporting against Target $\mathrm{B}$ (number of affected people), 56 States against target $\mathrm{C}$ (direct economic loss), 33 against target D (damages to Infrastructure and Disruptions to Basic Services), 56 against target $\mathrm{E}$ (national and local DRR Strategies), 36 against target $\mathrm{F}$ (Enhancement of International Cooperation to Developing Countries) and 48 States reporting against target $\mathrm{G}$ (availability of and access to multi-hazard early warning systems and disaster risk information and assessments).

7 UNDRR has here taken a broad definition. While not including States, local authorities may submit their commitments on the platform.

8 UNDRR, 'Voluntary commitments' <https://sendaicommitments.unisdr.org/> (open from $3^{1}$ December 2018).

9 UN 'Sendai Framework for Disaster Risk Reduction 2015-2030' (18 March 2015) UN Doc A/ CONF.224/ CRP.1. See especially para. 48(c). 
Although launching at the very end of the reporting year, the Voluntary Commitments platform saw some immediate engagement by stakeholders, as well as monitoring by the UNDRR. ${ }^{10}$

\section{Technical Guidance for Monitoring and Reporting on Progress in Achieving the Global Targets of the Sendai Framework for Disaster Risk Reduction}

Progress in relation to the seven global targets is being reported against a set of 38 indicators, developed by the OEIWG. ${ }^{11}$ As part of its work developing methodologies for measurements of progress, the UNDRR published the Technical guidance for monitoring and reporting on progress in achieving the global targets of the Sendai Framework for Disaster Risk Reduction in early 2018. ${ }^{12}$ The objective of the Technical Guidance is to enhance the consistency of the 'measurement of progress towards the global targets across countries and over the duration of the Sendai Framework and Sustainable Development Goals'. ${ }^{13}$ Building 'on the recommendations and deliberations of Member States in the OIEWG, on the technical documentation produced by the secretariat at the request of Members of the working group, [and] on the deliberations of the Inter-agency and Expert Group on SDG Indicators' the Guidance introduces 'standard methodologies' and 'minimum standards' in relation to the provision of data and interpretation of the set of indicators provided by the OIEWG. ${ }^{14}$

\section{3}

\section{Global Risk Assessment Framework}

One of the most significant aspects of the UNDRR's work in 2018 was the initiation of the development of a new Global Risk Assessment Framework (GRAF). The aim of the GRAF is 'to inform decision-making and transform behaviour'

10 For more details about the engagement with the platform from its launch until the first quarter of 2019, see UNDRR, 'Sendai Framework Voluntary Commitments Synthesis and Analysis Report 2019' (2019) < https://www.preventionweb.net/files/submissions/65545_ sfvcreport20190503light.pdf $>$.

11 These indicators have also been endorsed by the UNGA, see 'Report of the open-ended intergovernmental expert working group on indicators and terminology relating to disaster risk reduction' ( $\left.\mathrm{n}_{3}\right)$.

12 UNISDR, 'Technical guidance for monitoring and reporting on progress in achieving the global targets of the Sendai Framework for Disaster Risk Reduction' (March, 2018) $<$ https://www.unisdr.org/we/inform/publications/54970>.

13 Ibid., 3.

14 Ibid., 3. 
in order 'to achieve the global targets of all 2015 agreements: the Sendai Framework, Paris Agreement, the New Urban Agenda and the 2030 Agenda for Sustainable Development. ${ }^{15}$ The first preparatory meeting for the GRAF Expert Group was held in April 2018, followed by the initiation of the Expert Group in June 2018, where the Expert Group was tasked by producing a GRAF Implementation Roadmap 2019-2029. ${ }^{16}$ With the UNDRR having recognised the importance of broad consultations, a concept note, inviting 'all disaster risk reduction organizations and experts and users of risk to cooperate in the co-design and development of the GRAF' was finalised in September 2018. ${ }^{17}$

The concept note stated as the objectives of the GRAF " $[\mathrm{t}] \mathrm{o}$ improve understanding of complex risk and concatenating vulnerabilities in disaster environments'; ' $[\mathrm{t}] \mathrm{o}$ provide decision makers with actionable insights and access to products, tools, demonstrations and scenarios at all scales (spatial and temporal)'; '[t]o support decision-makers to maximise synergies across the implementation monitoring, follow up and review, as well as achievement of the targets and deliverables of the 2030 Agenda, the Paris Agreement, the New Urban Agenda and the Sendai Framework'; '[t]o build, and increase trust and confidence in, multi-sectoral risk assessments in an inclusive, evidence informed, open process'; ' $[\mathrm{t}$ ] foster a culture of inclusive, collaborative, and proactive behaviour based on interdisciplinary systems thinking and decision science'; and ' $[t]$ o mobilize finance and de-risk investments to enable risk-informed sustainable development'. ${ }^{18}$

\section{$4 \quad$ Regional Platforms and Events}

The UNDRR held, or supported the organisation of, a number of significant meetings throughout $2018 .{ }^{19}$ In addition to specific forums, ${ }^{20}$ it supported the organisation of the Regional Platforms, which play a central role in coordinating

15 UNISDR, 'GRAF concept note September 2018' (2018) (on file with author), 1.

16 For the selection criteria of the Expert Working Group, see ibid., 20.

17 Ibid., 1. The concept note identifies 'seven (7) major groups of stakeholders that have been initially identified for the design, development and implementation of the GRAF', namely the UN system, international organisations, national institutions, local authorities, the private sector, civil society, and Science and research (at 21). Introduction to GRAF can be found in UNDRR, 'Global Assessment Report on Disaster Risk Reduction 2019' (UN 2019) Section 2.5.

18 Ibid. (UNISDR), 2.

19 For further details, see UNDRR, 'Calendar of Events' <https://www.unisdr.org/we/inform/ events>.

20 For example the Technical forum to support monitoring of the Sendai Framework for Risk Reduction (Bonn, Germany, 9 December 2018) <https://www.unisdr.org/archive/62755>. 
and furthering the implementation of SFDRR on a regional level, with clear links to national and international efforts.

In 2018, the Regional Platforms included the Africa Arab Platform on DRR (Tunisia 9-13 October 2018), which concluded with the adoption of the Tunis Declaration on accelerating the implementation of the Sendai Framework for Disaster Risk Reduction 2015-2030, and the Africa Regional Strategy for Disaster Risk Reduction; ${ }^{21}$ the Asian Ministerial Conference for Disaster Risk Reduction (Ulaanbaatar, Mongolia 3-6 July 2018), which concluded with the Ulaanbaatar Declaration and the Regional Action Plan 2018-2020;22 the Regional Platform for DRR in the Americas (Cartagena, Colombia, 20-22 June 2018), which adopted the Cartagena Declaration, reaffirming their commitment to implementing the $2015^{-2020}$ Regional Action Plan; ${ }^{23}$ and European Forum for Disaster Risk Reduction (Rome, Italy, 21-23 November 2018), which concluded with the adoption of the Rome Declaration of Stakeholders: Securing Europe's Prosperity - Reducing Risk Of Disasters. ${ }^{24}$ The UNDRR also supported the organisation the Central Asia and South Caucasus Sub-regional Platform for Disaster Risk Reduction (Yerevan, Armenia, $26-27$ June 2018). ${ }^{25}$

In addition to adopting their respective key instruments, the Regional Platforms also served an important function in establishing the various regions' priorities before the 2019 Global Platform for DRR.

21 This conference was the first joint Platform between Africa and the Arab States and was co-organised by the Republic of Tunisia and UNDRR in collaboration with the African Union Commission and the League of Arab States. All outcome documents from this Platform are available at $<$ https://www.unisdr.org/conference/2018/afrp-acdrr $>$.

22 The conference was the eighth session of the Asian Ministerial Conference for Disaster Risk Reduction and co-hosted by the Government of Mongolia and UNDRR. All outcome documents from this Platform are available at <https://www.unisdr.org/conference/2018/ amcdrr>.

23 The conference was the Sixth Session of the Regional Platform for Disaster Risk Reduction in the Americas and hosted by the Colombian Government in cooperation with UNDRR. More details and outcome documents are available at $<\mathrm{http} / /$ eird.org/pri8/ eng/>.

24 The conference was co-organised by UNDRR and the Government of Italy. More information and conference documents are available at <https://www.unisdr.org/confert ence/2018/efdrr>.

25 More information and conference documents are available at $<$ https://www.unisdr.org/ conference $/ 2018 /$ casc $>$. 